EGU21-675

https://doi.org/10.5194/egusphere-egu21-675

EGU General Assembly 2021

(c) Author(s) 2021. This work is distributed under

the Creative Commons Attribution 4.0 License.

\title{
The role of irrigation expansion on historical climate change during the last 115 years: insights from CMIP6
}

\author{
Amen Al-Yaari ${ }^{1,2}$, Agnes Ducharne ${ }^{1,2}$, Wim Thiery ${ }^{3}$, Frederique Cheruy ${ }^{2,4}$, and David Lawrence ${ }^{5}$ \\ ${ }^{1}$ Sorbonne, METIS, METIS, Paris, France (amen.al-yaari@upmc.fr) \\ ${ }^{2}$ IPSL (Institut Pierre Simon Laplace), Sorbonne Université, CNRS, Paris, France \\ ${ }^{3}$ Vrije Universiteit Brussel, Department of hydrology and hydraulic engineering \\ ${ }^{4}$ LMD (Laboratoire de Météorologie Dynamique), Sorbonne Université, ENS, PSL Université, École polytechnique, Institut \\ Polytechnique de Paris, CNRS, Paris, France \\ ${ }^{5}$ National Center for Atmospheric Research, Boulder, CO USA
}

Irrigated areas have increased, faster than the growth of the world population, from around 0.63 million $\mathrm{km}^{2}$ at the start of the 20th century to 3.1 million $\mathrm{km}^{2}$ of land in 2005 , that is five times of area in $1900\left(0.6\right.$ million $\left.\mathrm{km}^{2}\right)$. Irrigation is one of the land management practices with the largest biogeochemical and biogeophysical effects on climate. However, incorporating land management factors (including irrigation) into most of the stateDofDtheDart climate models under the Coupled Model Intercomparison Project, Phase 6 (CMIP6) coordinated by the World Climate Research Programme (WCRP) is still overlooked. To our best knowledge, three models, however, take into account irrigation activities: namely NorESM2DLM, GISSDE2DH, and CESM2. The overall objective of the study is to investigate the role of irrigation on climate change at the global scale by looking at temporal trends of Essential Climate variables (ECVs) that characterize the Earth's climate (Evapotranspiration, leaf area index, precipitation, soil moisture, radiation, and air temperature) over the last 115 years (i.e. 1900-2014). Within this investigation, we compared models with irrigation vs. models without irrigation using 20 models from different CMIP6 experiments: coupled land-atmosphere amip (observed sea surface temperatures and sea ice concentrations), coupled land-atmosphere-ocean historical simulation, and offline land-hist (land only simulations). Temporal trends over the 1900-2014 period were computed then spatially binned by the "FAO Global Map of Irrigation Areas", which represents area equipped for irrigation expressed as percentage of total area around the year 2005. For the three CMIP6 experiments, the three models with irrigation switched on showed similar and distinguished behavior from all other models with irrigation switched off over intensively irrigated areas: mean annual evapotranspiration and soil moisture increased over time (positive trends vs. negative or no trends for all other none-irrigation models). This increase in evapotranspiration over time was reflected in the negative trends (i.e. cooling) of annual maximum air temperature for the irrigation models vs. positive trends for most of the none-irrigation models. The ET temporal positive trends over intensively irrigated areas were detected and confirmed by four different satellite-based ET products. The consistent results among the three experiments and confirmed by different satellite data imply the importance of incorporating anthropogenic factors in the next generation of climate models. 
